\title{
SHORT COMMUNICATION: TOWARDS DEVELOPMENT OF Elaeis guineensis CHROMOSOME-ARM SPECIFIC MARKERS AND THEIR UTILITY ACROSS THE Elaeis GENUS
}

\author{
NOORHARIZA MOHD ZAKI*; SINGH, ${ }^{*}$; NORDIANA HANIM MOHD NOR*; MUHAMMAD AZWAN \\ ZULKIFLI*; STEVEN W SMITH**; TRUDE SCHWARZACHER ${ }^{\star}$; MADON, $M^{*}$ \\ and HESLOP-HARRISON, J S
}

\begin{abstract}
The development of Elaeis guineensis chromosome-arm specific markers is required for linking the genetic, sequence and chromosomal maps, valuable for comparative studies, hybridisation and breeding. Here, we aimed to develop strategies exploiting assembled short shotgun-sequence reads to identify markers for in situ hybridisation to identify arms and large-scale organisation of pseudo-chromosome 1. The conserved putative repetitive DNA sequence found through informatics analysis showed an extra intercalary band in one arm of pseudo-chromosome 1 in fluorescence the in situ hybridisation result. The results are a basis for establishing a North-South orientation of E. guineensis pseudo-chromosome. Furthermore, the ability of the newly developed markers for distinguishing both Elaeis species with in situ hybridisation showed their utility in identifying Elaeis hybrids.
\end{abstract}

Keywords: Elaeis guineensis, chromosome markers, in situ hybridisation, repetitive DNA.

Date received: 3 May 2017; Sent for revision: 5 May 2017; Received in final form: 23 August 2017; Accepted: 7 September 2017.

\section{INTRODUCTION}

Chromosome identification in plants is important for the construction of cytogenetic maps. Moreover, the reliable chromosome identity can be used as reference for demarcating possible structural differences, both inter- and intra-species (Ren et al., 2012) and provide unique insight into genome organisation in the context of chromosomes (Heslop Harrison and Schwarzacher, 2011). For oil palm (Elaeis guineensis; $2 \mathrm{n}=32$ ), with the exception

Malaysian Palm Oil Board,

6 Persiaran Institusi, Bandar Baru Bangi,

43000 Kajang, Selangor, Malaysia.

E-mail: maria@mpob.gov.my

** Orion Genomics, 4041 Forest Park Avenue, Saint Louis, Missouri 63108, USA.

* Department of Genetics, University of Leicester, Leicester LE1 7RH, United Kingdom. of one chromosome pair, the sub-metacentric chromosomes show near-continuous variation in size, so they cannot be identified morphologically. Study and identification of oil palm chromosomes started as early as the 1940s, using a very limited range of techniques. Two approaches that have been applied by previous researchers are by measuring the chromosome length (Sato, 1949; Sharma and Sarkar, 1956; Madon et al., 1995) and by localising a few families of repetitive DNA to try to identify chromosomes in the E. guineensis karyotype (Castilho et al., 2000).

One strategy to construct a molecular cytogenetic map and determine identity of each chromosome is to localise directly the DNA sequences on metaphase or pachytene chromosomes by fluorescence in situ hybridisation (FISH) which gives reliable results regardless of the chromosome size. In the cereals, use of 
repetitive DNA sequences for in situ hybridisation has been valuable to identify each chromosome arm in breeding lines (Ali et al., 2016). For many species, including oil palm (Castilho et al., 2000), many repetitive DNA sequences have been isolated from genomic DNA using restriction-satellites, polymerase chain reaction (PCR) amplification, or selection from clone libraries. However, apart from the $45 \mathrm{~S}$ which is located at the nucleolar organising region of the short chromosome and 5S rDNA hybridised on proximal of the longest chromosome (Castilho et al., 2000), in situ hybridisation with these repeats has not enabled chromosome arms to be identified uniquely in oil palm.

The oil palm genome paper (Singh et al., 2013) has re-assigned the 16 pairs of $E$. guineensis individual chromosomes into four groups; Group I: the largest chromosomes (hybridises to 5S rDNA at the proximal region); Group II: eight medium chromosomes; Group III: six small chromosomes and Group IV: small acrocentric chromosome (hybridise to 18S-25S rDNA). In the published 1.8 gigabase $(\mathrm{Gb})$ oil palm sequence, Singh et al. (2013) reported approximately $57 \%$ of the genome was unassembled and is likely to include mainly repetitive DNA sequences. In this study, we report the first chromosome-arm specific marker for pseudo-chromosome 1 of oil palm Elaeis guineensis isolated from repetitive regions of E. guineensis which was found to be conserved in the genome. The utility of the developed marker showed a potential application for distinguishing both Elaeis species. The results are a starting point towards constructing a cytogenetic map. This also allows the association of the physical chromosomes of E. guineensis with the pseudo-chromosomes obtained through genome sequencing. Such a map is important for basic genomic research, comparative genomics, evolutionary studies, and further assists in understanding the inheritance of specific traits in oil palm.

\section{MATERIALS AND METHOD}

\section{Plant Material}

The oil palm (E. guineensis) materials used for developing the DNA probes were published by Singh et al. (2013) and are currently maintained at the MPOB Research Station, Kluang, Johor, Malaysia. Genomic DNA was extracted and purified from a spear leaf using the modified CTAB method as described by Doyle and Doyle (1990).

\section{Universal Repetitive DNA Sequences}

The 18S rDNA gene $(1.7 \mathrm{~kb})$ was amplified from E. guineensis genomic DNA using a primer pair published by Chang et al. (2010)
(P1:5'-CGAACTGTGAAACTGCGAATGGC-3') and (P2:5'-TAGGAGCGACGGGCGGTGTG-3') and used as the probe to identify sites of the 45S rDNA. Clone pTa794, containing the $5 S$ rRNA genes and intergenic spacer from wheat (Gerlach and Dyer, 1980), was used as the $5 S$ rDNA probe. The synthetic oligomer (CCCTAAA) 6 was used to label the telomeres.

\section{Identification of Repetitive DNA Sequences}

A draft version of the P9 assembly [unpublished; an updated version of the assembly in Singh et al. (2013)] was analysed for repetitive elements with the REPET package (https://urgi.versailles.inra. $\mathrm{fr} /$ Projects/URGI-softwares/REPET) using the TEdenovo module which resulted in 0.54 GB of consensus repetitive sequence averaging $826 \mathrm{bp}$ in length. These repetitive sequences were annotated using the TEannotate module, and were mapped back to the final P9 assembly.

\section{Conversion of Repetitive Unique Sequence into FISH Probes}

One primer pair flanking a putative repetitive sequence (Eg9CEN-length $354 \mathrm{bp}$ ) was designed; Eg9CEN-F: C C A T A T G G G T T G G T T G T C C and Eg9CEN-R: A C A G C G A C T C A T T C T T C T C C. The probe Eg9CEN was amplified from E. guineensis and E. oleifera genomic DNA by PCR using the following programme: $3 \mathrm{~min} 95^{\circ} \mathrm{C}$, 30 cycles of $\left(30 \mathrm{~s} 95^{\circ} \mathrm{C}, 30 \mathrm{~s} 58^{\circ} \mathrm{C}, 1 \mathrm{~min} 30 \mathrm{~s} 72^{\circ} \mathrm{C}\right)$, $1 \mathrm{~min} 72^{\circ} \mathrm{C}$. PCR products were separated on a $1 \%$ agarose gel electrophoresis and isolated with the E.Z.N.A Gel Extraction Kit (Omega) as described by the manufacturer. Purified amplicon was stored at $-20^{\circ} \mathrm{C}$ until use.

\section{Probe Labelling}

Synthetic oligomers and PCR products were labelled with digoxigenin-11-dUTP (Roche Diagnostic, Basel, Switzerland) or biotin-16-dUTP (Roche Diagnostic) using the BioPrime ${ }^{\circledR}$ Array CGH Labelling System (Invitrogen, California, USA) according to the manufacturer's instructions.

\section{Preparation of Chromosome Spreads}

Chromosome spreads preparation were made from root tips from both adults and seedlings of E. guineensis as well as adult E. oleifera by using technique modified from Madon et al. (1995) and Schwarzacher and Heslop-Harrison (2000). Root tips were pre-treated with $2 \mathrm{mM}$ 8-hydroxyquinoline for 5-6 hr at $18^{\circ} \mathrm{C}$ and fixed in 3:1 ethanol: glacial acetic acid (v/v) and stored in $70 \%$ ethanol at $4^{\circ} \mathrm{C}$ until further use. The root tips were washed several times with citric acid-citrate buffer, $\mathrm{pH}$ 4.6 and digested at $37^{\circ} \mathrm{C}$ for up to $4 \mathrm{hr}$ in enzyme 
solutions containing $2 \%-4 \%(\mathrm{w} / \mathrm{v})$ cellulase (Sigma C1184; final concentration 10-20 $\mathrm{U} \mathrm{ml}^{-1}$ ), $0.2 \%$ (w/v) 'Onozuka' RS cellulase (final concentration 10 $\left.\mathrm{U} \mathrm{ml}^{-1}\right), 3 \%(\mathrm{v} / \mathrm{v})$ pectinase (Sigma P4716 from Aspergillus niger; solution in $40 \%$ glycerol, final concentration 15-20 $\mathrm{U} \mathrm{ml}^{-1}$ ) in citric acid-citrate buffer. Mitotic chromosomes were spread by squashing and heating onto pre-cleaned glass slide in a drop of $45 \%$ or $60 \%$ acetic acid under a cover slip, frozen before flicking off the cover slip, and left to air-dry before using for FISH.

\section{Fluorescence in situ Hybridisation}

In situ hybridisation was performed according to Schwarzacher and Heslop-Harrison (2000) with minor modifications. A total of $40 \mu \mathrm{l}$ probe was applied per slide, containing $50 \%(\mathrm{v} / \mathrm{v})$ formamide, $20 \%$ (w/v) dextran sulphate, $2 X$ saline sodium citrate (SSC, $0.3 \mathrm{M} \mathrm{NaCl}, 0.03 \mathrm{M}$ sodium citrate), $0.05 \mu \mathrm{g}$ of salmon sperm DNA, $0.25 \%(\mathrm{w} / \mathrm{v})$ sodium dodecyl sulphate, $0.25 \mathrm{mM}$ ethylenediamine-tetraacetic acid and 25-100 ng probe. The probe mixture was denatured for $10 \mathrm{~min}$ at $80^{\circ} \mathrm{C}$ and immediately transferred to ice. Probe and chromosomal DNA were denatured together on a heated block (Thermo Fisher Scientific) at $72^{\circ} \mathrm{C}$ for 5 min under plastic cover slips, allowed to cool to hybridisation temperature of $37^{\circ} \mathrm{C}$ overnight. A series of posthybridisation washes were carried out with 2 X SSC and $0.1 \mathrm{X}$ SSC at $42{ }^{\circ} \mathrm{C}$. Hybridisation sites for biotin and digoxigenin-labeled probes were detected with $2 \mu \mathrm{g} \mathrm{ml}{ }^{-1}$ streptavidin conjugated to Alexa 594 (Molecular Probes, Thermo Fisher Scientific) and $4 \mu \mathrm{g} \mathrm{ml} \mathrm{m}^{-1}$ anti-digoxigenin conjugated to fluorescein isothiocyanate (FITC, Roche Diagnostic) respectively. DAPI (4,6-diamidino-2-phenylindole) in CITIFLUOR AF1 (Chem Lab,) antifade solution was used to counterstain the chromosomes. At least two slides with 15 high quality metaphases were hybridised and analysed for each probe and species combination.

\section{Image Acquisition}

Slides were examined using a Nikon Eclipse 80i fluorescent microscope. Three Nikon filters were used for the observation, UV-2E / C (emission at 435-485) for DAPI, B-2E/C (emission at 515555 ) for fluorescein and G-2E/C (emission at 590650) for Alexa 594. Images were acquired with Nikon DS-Qi1 Digital camera and NIS elements $A R$, version 3.2 software. The individual channels were pseudo-coloured to visualise the sites of probe hybridisation. The images were processed using Adobe Photoshop CS5 software (Adobe System Inc., http://www.adobe.com) using cropping and functions that affect the whole image equally.

\section{RESULTS AND DISCUSSION}

\section{A Chromosome-arm Specific Marker for E. guineensis Pseudo-chromosome 1}

Analysis of the E. guineensis P9 sequence assembly identified a region (named Eg9CEN) of 354 bp with 1703 copies per genome. The amplification within the fragment by PCR showed a single band amplicon with expected size (c.330 bp) (Figure 1). In situ hybridisation with Eg9CEN showed a broad centromeric hybridisation signal observed on all 32 chromosomes, notably with a conserved and distinct intercalary site of hybridisation detected on the opposite arm to the $5 S$ rDNA site (Figure 2a). Hybridisation with Eg9CEN and the telomere (CCCTAAA) (Figure 2b) also showed the intercalary site distal on the longest chromosome.

The Eg9CEN sequence, derived from the bioinformatics analysis, showed 95\% homology to five of the repetitive DNA sequences isolated by screening clones for repetitive sequences from genomic DNA, pEgKB23, pEgKB15, pEgKB1, pEgKB14, and pEgKB19 families. In the consensus region, there were no indels between any of the five sequences, and no unique single nucleotide

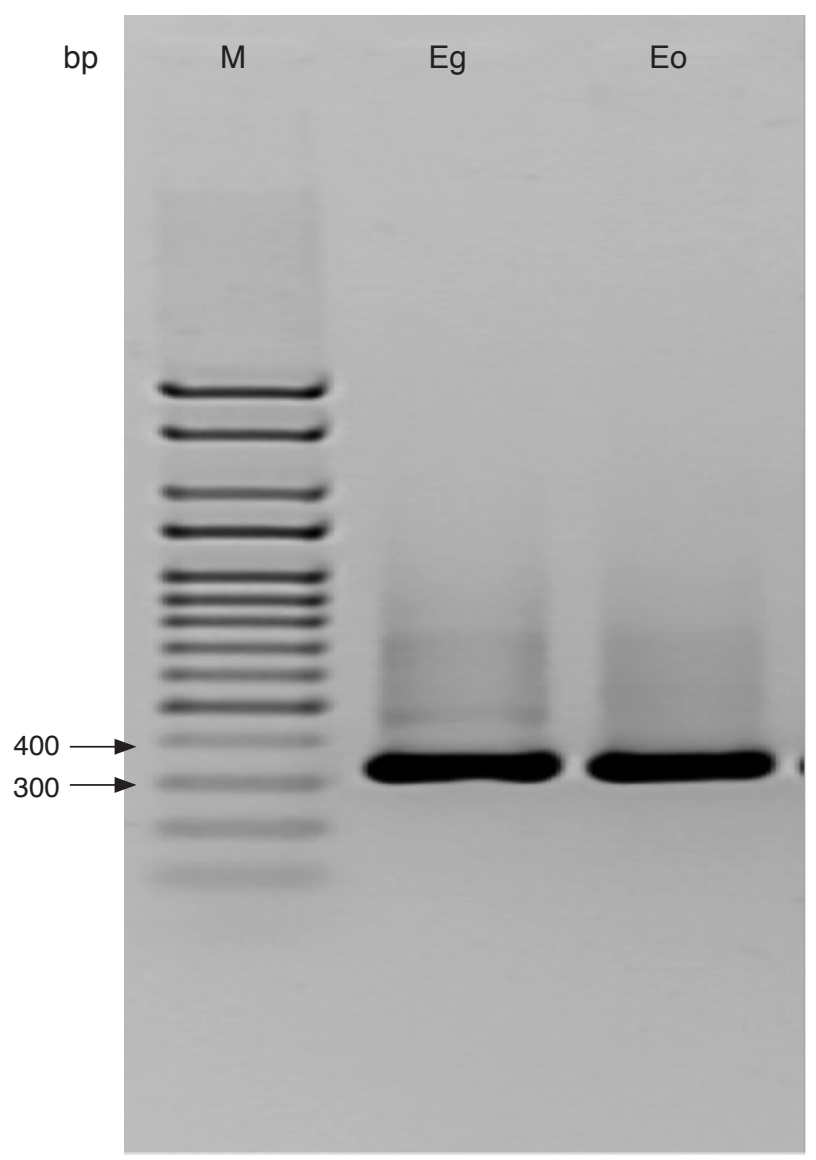

Figure 1. Polymerase chain reaction (PCR) amplification of Eg9CEN from genomic DNA of E. guineensis (Eg) and E. oleifera (Eo). A similar band (c. $330 \mathrm{bp}$ ) is amplified by the primer pair from both species. 

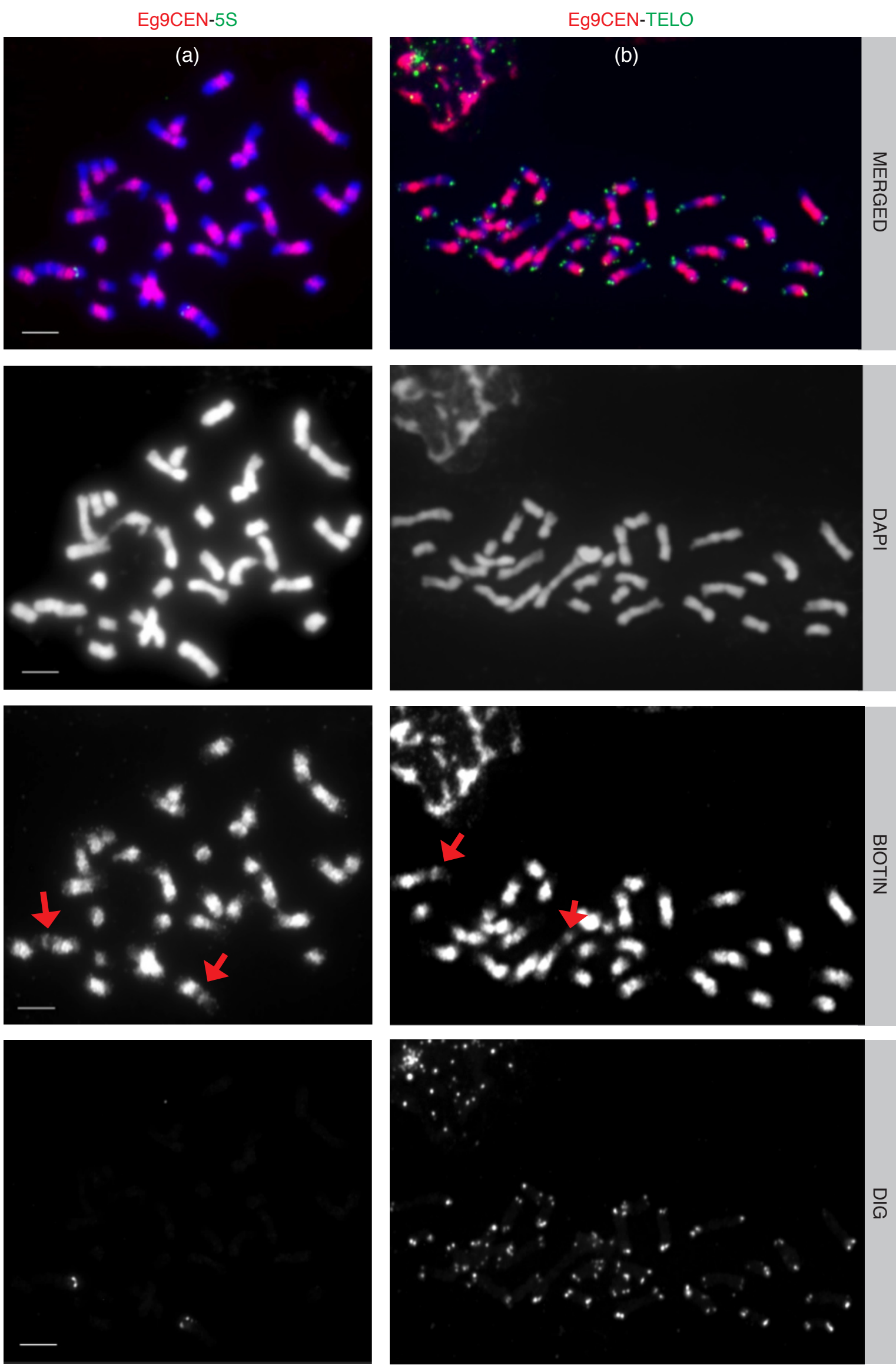

Figure 2. In situ hybridisation on metaphase chromosomes of Elaeis guineensis ( $2 n=32)$. Eg9CEN (red signal) probe is hybridised with the $5 S$ rDNA (green signal) probe (a) and a synthetic DNA telomere (green signal) probe (b). DAPI counterstaining shows the 32 metaphase chromosomes. Red arrow shows the intercalary site of Eg9CEN. 
polymorphisms in Eg9CEN, although pEgKB23 was some 130 bp longer.

Both the 5S rDNA and the Eg9CEN intercalary site enabled identification of pseudo-chromosome 1 , and its North and South or long and short arm orientation. Thus, the repetitive probe identification strategy from the whole genome assembly helps to validate the current linkage map and assembly.

\section{Comparative Analysis to Differentiate Two Elaeis Species}

PCR amplification of the Eg9CEN unique repetitive probe produced a similar single band, length (c. $330 \mathrm{bp}$ ) in both E. guineensis and E. oleifera (Figure 1). However, the localisation of Eg9CEN by in situ hybridisation on the E. oleifera physical chromosome along with the synthetic telomere, 18S-25S rDNA and 5S rDNA showed a contrasting distribution between the two Elaeis species (Figures 3 and 4). Both rDNA hybridisation sites on E. oleifera were similar as reported for E. guineensis (Castilho et al., 2000), however, it was noticeable that $5 \mathrm{~S}$ hybridisation signal on E. oleifera chromosome is much stronger compared to E. guineensis. As for $\mathrm{Eg} 9 \mathrm{CEN}$, the probe that showed a unique

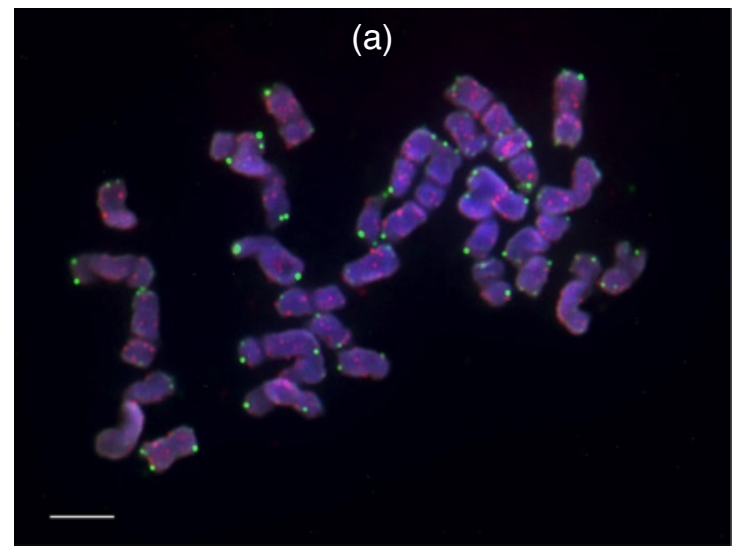

hybridisation pattern on pseudo-chromosome 1 of E. guineensis, exhibited a dispersed distribution over the whole of the 16 E. oleifera chromosomes. In 1999, Madon et al. successfully discriminated the two sets of chromosomes in interspecific hybrid palms via genomic in situ hybridisation (GISH) approach, where a total genomic DNA was used as a probe. The repetitive DNA sequence of Eg9CEN established in this study is most likely a component of the genomic DNA probe that allows Elaeis discrimination. Moreover, the defined nature of the Eg9CEN probe, showing substantial differences in the hybridisation between the species, makes it a valuable species-specific marker for identifying parental or ancestral chromosomes in hybrids as well as looking for introgression, or identifying any inter-specific translocation events in oil palm hybrid derivatives.

\section{CONCLUSION}

Various studies have identified tandemly repeated and dispersed transposon-related repetitive elements from both genomic DNA and informatic studies (Biscotti et al., 2015). This study shows that

Figure 3. In situ hybridisation of Eg9CEN (red signal) on E. oleifera $(2 n=32)(a)$ and E. guineensis (b) chromosomes. Different hybridisation patterns of Eg9CEN are observed in these two Elaeis species.

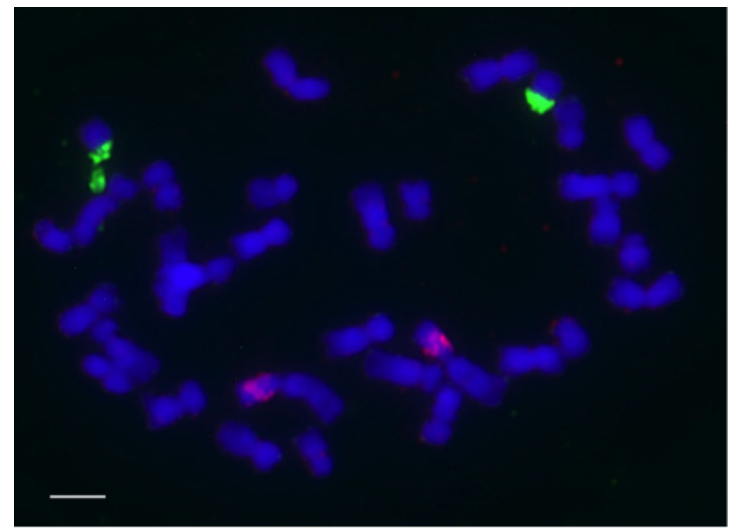

Figure 4. The 5S (red) and 45S rDNA (green) signals observed at a single pair of chromosomes on different E. oleifera metaphase chromosomes. informatic analysis allows sequence-independent identification of abundant repetitive DNA sequences whole genome assemblies. We were able to identify an abundant sequence, with no known homology to known repetitive element classes, that acted as a chromosome-arm specific marker for Elaeis guineensis pseudo-chromosome 1. Notably, the Eg9CEN sequence, a consensus extracted from the bioinformatics analysis rather than being a single cloned sequences, showed a more uniform hybridisation pattern than the 95\% similar pEgKB23 clone published by Castilho et al. (2000). Previously, the intercalary site on pseudo-chromosome 1 was not distinguished when the clones were used in the in situ hybridisation, despite the similarity. 
Several authors have discussed the occurrence of either chromosome-specific or region-specific variants of repetitive DNA sequences (Kuhn et al., 2007), and we have considered the value of making a 'consensus' sequences which may never exist in a genome. Given the similarity $(95 \%)$ between the sequences, even with highly stringent hybridisation and wash conditions, in situ (or indeed Southern) hybridisation is unlikely to distinguish robustly between the probes, so it is interesting that the cloned probes gave a less specific signal.

The strategy to generate repetitive probes with characteristic chromosomal hybridisation patterns provides a basis for establishing the NorthSouth orientation of the E. guineensis pseudochromosomes. It is likely that extensions of the bioinformatic analysis based on high-coverage sequence assemblies can be extended to many if not all other chromosome arms. Furthermore, the utility of the developed marker showed a potential application for distinguishing chromosome in the interspecific hybrid E. oleifera x E. guineensis. This finding is important for basic genomic research comparative genomics, evolutionary studies and assists in understanding the inheritance of specific traits in oil palm.

\section{ACKNOWLEDGEMENT}

The authors would like to thank the DirectorGeneral of MPOB for permission to publish this article and research assistants of MPOB involved in this work, particularly Zainab Anip and Mohd Razali Mohd Nor. The first author would like to thank MPOB for Ph.D fellowship.

\section{REFERENCES}

ALI, N; HESLOP-HARRISON, J S; AHMAD, $\mathrm{H}$; GRAYBOSCH, R A; HEIN, $\mathrm{G}$ L and SCHWARZACHER, T (2016). Introgression of chromosome segments from multiple alien species in wheat breeding lines with wheat streak mosaic virus resistance. Heredity, 117(2): 114-123.

BISCOTTI, MA;OLMO, EandHESLOP-HARRISON, J S (2015). Repetitive DNA in eukaryotic genomes. Chromosome Research, 23(3): 415-420.

CASTILHO, A; VERSHININ, A V and HESLOPHARRISON, J S (2000). Repetitive DNA and the chromosomes in the genome of oil palm (Elaeis guineensis). Annals of Botany, 85(6): 837-844.

CHANG, K D; FANG, S A; CHANG, F C and CHUNG, M C (2010). Chromosomal conservation and sequence diversity of ribosomal RNA genes of two distant Oryza species. Genomics, 96(3): 181-90.
DOYLE, J J and DOYLE, J L (1990). Isolation of plant DNA from fresh tissue. Focus, 12: 13-15.

GERLACH, W L and DYER, T A (1980). Sequence organization of the repeating units in the nucleus of wheat which contain 5S rRNA genes. Nucleic Acids Res., 8: 4851-4865.

HESLOP-HARRISON, J S and SCHWARZACHER, $\mathrm{T}$ (2011). Organisation of the plant genome in chromosomes. Plant J., 66(1): 18-33.

KUHN, G C S; FRANCO, F F; MANFRIN, M H; MOREIRA-FILHO, O and SENE, F M (2007). Low rates of homogenization of the DBC-150 satellite DNA family restricted to a single pair of micro -chromosomes in species from the Drosophila buzzatii cluster. Chromosome Research, 15: 457-46.

MADON, M; CLYDE, M M and CHEAH, S C (1999). Application of genomic in situ hybridization (GISH) on Elaeis hybrids. J. Oil Palm Res. (Special Issue): 7480 .

MADON, M; CLYDE, M M and CHEAH, S C (1995). Cytological analysis of Elaeis guineensis (tenera) chromosomes. Elaeis, 7(2): 122-134.

REN, Y; ZHAO, H; KOU, Q; JIANG, J; GUO, S; ZHANG, H; HOU, W; ZOU, X; SUN, H; GONG, G; LEVI, A and XU, Y (2012). A high resolution genetic map anchoring scaffolds of the sequenced watermelon genome. PLoS One, 7(1): e29453.

SATO, D (1949). Karyotype alteration and phylogeny VI; karyotype analysis in Palmae. Cytologia, 12: 174186.

SCHWARZACHER, T and HESLOP-HARRISON, J S (2000). Practical in situ Hybridization. BIOS Scientific Publishers Ltd, Abindgdon, UK.

SHARMA, A K and SARKAR, S K (1956). Cytology of different species of palms and its bearings on the solutions of the problems of phylogeny and speciation. Genetica, 28: 361-488.

SINGH, R; ONG-ABDULLAH, M; LOW, E T L; MANAF, M A A; ROSLI, R; NOOKIAH, R; OOI, C L; OOI, S E; CHAN, K L; HALIM, M A; AZIZI, N; NAGAPPAN, J; BACHER B; LAKEY, N; SMITH, S W; HE, D; HOGAN, M; BUDIMAN, M A; LEE, E K; SALLE, R D; KUDRNA, D; GOICOECHEA, J L; WING, R A; WILSON, R L; FULTON, R S; ORDWAY, J M; MARTIENSSEN, $\mathrm{R} A$ and SAMBANTHAMURTHI, R (2013). Oil palm genome sequence reveals divergence of interfertile species in old and new worlds. Nature. 500 (7462): 335-339. 